\title{
Assessment of abruptio placentae cases in M.G.M. healthcare institute, Kalamboli: A cross-sectional study
}

\author{
Shaifali Patil ${ }^{1}$, Anup Kapse ${ }^{2, *}$ \\ ${ }^{\mathbf{1}}$ Associate Professor, ${ }^{2}$ Junior Resident, Dept. of Obstetrics and Gynecology, MGM Hospital, Kalamboli, Navi Mumbai, \\ Maharashtra, India
}

*Corresponding Author:

Email: researchexpert2018@gmail.com

Received: $22^{\text {nd }}$ February, 2018

Accepted: $13^{\text {th }}$ April, 2018

\begin{abstract}
Introduction: Abruptio placenta is a serious obstetric complication which is characterised by the premature separation of the placenta. It is also associated with premature deliveries, maternal and fetal morbidities. Multiple factors are known to be associated with increased risk of placental abruption as alcohol and cocaine use and cigarette smoking, and nutritional deficiencies etc.

Materials and Methods: It was a retrospective study conducted among 47 cases of abruptio placentae admitted under the department of obstetrics and gynecology, in MGM Hospital, Kalamboli, Navi Mumbai, for a period of 2 years (December 2015 to December 2017).

Results: The mean age of presentation was reported to be 26.59 years. The incidence of abruptio placentae was found to be least after the age of 35 years (Table 1). Majority of cases were multigravida, while $32 \%$ cases presented with AP were primigravida. Among the multigravida cases, the majority of cases were of gravida 2 and 3 and the mean gravida order was 2.4.

Conclusions: From the current study, we can conclude that multiparty, cesarean section, previous abortion, and placental abruption can be considered at high risk of placental abruption.
\end{abstract}

Keywords: Abruptio placenta, Obstetric complications, Premature delivery, Maternal mortality, Maternal morbidity.

\section{Introduction}

Abruptio placenta is a serious obstetric complication which is characterised by the premature separation of the placenta that occurs in about $1-2$ per 100 pregnancies. ${ }^{1}$ It is a major obstetric complication associated with increased risk of fetal and maternal morbidity and mortality globally, especially in developing countries. Over 50\% of all perinatal deaths attributed to abruptio placentae pregnancies are accompanied by premature delivery. ${ }^{2-4}$ However, rates as high as $4.5 \%$ have been reported in developing countries. $^{5}$ The etiology of placental abruption is unknown, but it occurs more for equinity among smokers, in hypertensive pregnancies, in pregnancies with intra uterine growth restriction (IUGR), in instances of trauma, with advancing maternal age, with male fetuses, and in women with a previous placental abruption. ${ }^{6}$ Multiple factors are known to be associated with increased risk of placental abruption as alcohol and cocaine use and cigarette smoking, but there are fewer studies about the importance of opioid abuse in placental abruption. ${ }^{7}$ Some studies observed nutritional deficiencies as a risk factor for placental abruption, and perinatal morbidity and mortality due to placental abruption can be reduced by good antenatal care and improved nutrition. ${ }^{89}$ The signs and symptoms of AP vary depending on the severity of bleeding and degree of separation of the placenta. The most common presentations include vaginal bleeding, uterine and abdominal pain and tenderness, abnormal uterine contractions, premature labor, maternal hemodynamic instability, fetal distress, and fetal death. ${ }^{5}$ Antepartum hemorrhage (APH) is a grave obstetrical emergency. Maternal and perinatal complications in APH are anemia, malpresentation, post-partum hemorrhage, shock, low birth weight, intrauterine death, and birth asphyxia. ${ }^{6}$ The present retrospective study was conducted to assess socio-demographic profile, risk factors associated and various modes of presentations of abruptio placentae cases. And hence its consequences on the fetal and maternal outcome and to identify the associated risk factors.

\section{Materials and Methods}

It was a retrospective study conducted among 47 cases of abruptio placentae admitted under the department of obstetrics and gynecology, in MGM Hospital, Kalamboli, Navi Mumbai, for a period of 2 years (December 2015 to December 2017). The study included all the diagnosed cases of abruptio placenta during the study period. We defined abruptio placentae as complete or partial separation of normally located placenta before parturition. AP was diagnosed based on clinical signs and symptoms of vaginal bleeding, tense and tender abdomen, hypertonic uterus, and confirmed at delivery by the local examination of placenta for separation and presence of a retroplacental hematoma. All the relevant clinical information was collected: Maternal age, parity, gestational age at delivery, birth weight, and medical complications such as diabetes mellitus, hypertension and thyroid disease, general physical examination, and abdominal and pelvic 
examination. Relevant investigations such as laboratory tests like hemoglobin $(\mathrm{Hb})$, peripheral smear, platelet count, coagulation profile, kidney function tests, liver function tests, urine examination, and ultrasonography (USG) imaging and cardiotocography were performed especially to assess fetal well-being. The data was entered and analyzed using MS-Excel software.

\section{Results}

The present study was conducted among 47 diagnosed cases of abruptio placentae admitted under the department of obstetrics and gynecology during the period of December 2015 to December 2017 in MGM Hospital, Kalamboli, Navi Mumbai. Majority of the cases belonged to 20-25 years of age group followed by 26-30 years of age group. The mean age of presentation was reported to be 26.59 years. The incidence of abruptio placentae was found to be least after the age of 35 years (Table 1). Majority of cases were multigravida, while $32 \%$ cases presented with AP were primigravida. Among the multigravida cases, the majority of cases were of gravida 2 and 3 and the mean gravida order was 2.4 (Table 3). When we assessed their gestational age at the time of presentation, we found that majority of cases presented between 36-40 weeks of gestation, followed by 31-35 weeks of gestation, with the mean gestational age of 34.1 weeks. The occurrence of cases was found to be minimal before a gestational age of 30 weeks (Table 2). Most of the cases presented with complaints of bleeding per vaginum $(93.6 \%)$, followed by abdominal pain $(80.86 \%)$. $68.02 \%$ cases were associated with pregnancy-induced hypertension, whereas $29.78 \%$ cases were having a history of abortions during their past pregnancies (Fig. 1). 21.27\% cases were found to be moderately anemic with hemoglobin levels between 7 to $10 \mathrm{mg} / \mathrm{dl}$, while $8.51 \%$ cases reported being severely anemic. Anemia was reported probably due to bleeding during the course of their disease (Table 4). 82.97\% cases of abruptio placentae were managed using lower section caesarian section, followed by $17 \%$ cases by vaginal delivery (Fig. 2). We also assessed outcomes of these cases. 34 $(72.34 \%)$ cases delivered live-born fetuses out of which $19(55.88 \%)$ of the fetuses required specialized care under NICU. The mean weight of live born fetuses was reported to be $1.98 \mathrm{Kg}$. 13 cases $(27.65 \%)$ resulted in intrauterine fetal deaths (Table 5).

Table 1: Distribution of cases according to their age groups

\begin{tabular}{|l|c|c|}
\hline \multicolumn{1}{|c|}{ Age group } & $\begin{array}{c}\text { Number of } \\
\text { cases }\end{array}$ & Percentage \\
\hline 21-25 years & 23 & $48.93 \%$ \\
\hline 26-30 years & 16 & $34.04 \%$ \\
\hline 31-35 years & 5 & $10.63 \%$ \\
\hline More than 36 & 3 & $6.38 \%$ \\
\hline Total & 47 & $100 \%$ \\
\hline Mean age & \multicolumn{2}{|c|}{26.59 years } \\
\hline
\end{tabular}

Indian Journal of Obstetrics and Gynecology Research, July-September, 2018;5(3):335-338

Table 5: Distribution of cases according to their outcome

\begin{tabular}{|l|c|c|}
\hline Outcome measures & $\begin{array}{l}\text { Number } \\
\text { of cases }\end{array}$ & Percentage \\
\hline Live-born fetuses & 34 & $72.34 \%$ \\
\hline $\begin{array}{l}\text { Live-born fetuses } \\
\text { requiring specialized care } \\
\text { in NICU }\end{array}$ & 19 & $55.88 \%$ \\
\hline Intra-uterine fetal deaths & 13 & $27.65 \%$ \\
\hline $\begin{array}{l}\text { Mean weight of fetuses } \\
\text { born }\end{array}$ & \multicolumn{2}{|c|}{$1.98 \mathrm{Kg}$} \\
\hline
\end{tabular}

Table 4: Distribution of cases according to their clinical presentation

\begin{tabular}{|l|c|c|}
\hline Hemoglobin levels & $\begin{array}{c}\text { Number } \\
\text { of cases }\end{array}$ & Percentage \\
\hline $\begin{array}{l}\text { Moderate Anemia (Hb: } \\
7-10 \mathrm{mg} / \mathrm{dl})\end{array}$ & 10 & $21.27 \%$ \\
\hline $\begin{array}{l}\text { Severe anemia }(\mathrm{Hb}: \\
\text { less than 7 mg/dl) }\end{array}$ & 4 & $8.51 \%$ \\
\hline
\end{tabular}
gestational age at presentation

\begin{tabular}{|l|c|c|}
\hline \multicolumn{1}{|c|}{ Gestational age } & $\begin{array}{c}\text { Number of } \\
\text { cases }\end{array}$ & Percentage \\
\hline Less than 25 Weeks & 1 & $2.12 \%$ \\
\hline 26-30 Weeks & 9 & $19.14 \%$ \\
\hline $31-35$ Weeks & 17 & $36.17 \%$ \\
\hline $36-40$ & 20 & $42.55 \%$ \\
\hline Total & 47 & $100 \%$ \\
\hline Mean gestational age & \multicolumn{2}{|c|}{34.01 weeks } \\
\hline
\end{tabular}

Table 3: Distribution of cases according to their order of gravida

\begin{tabular}{|l|c|c|}
\hline \multicolumn{1}{|c|}{ Order of gravida } & $\begin{array}{c}\text { Number of } \\
\text { cases }\end{array}$ & Percentage \\
\hline Primigravida & 15 & $31.91 \%$ \\
\hline Gravida 2-3 & 20 & $42.55 \%$ \\
\hline Gravida 4-5 & 11 & $23.4 \%$ \\
\hline Gravida more than 5 & 1 & $2.12 \%$ \\
\hline Total & 47 & $100 \%$ \\
\hline $\begin{array}{l}\text { Mean order of } \\
\text { gravida }\end{array}$ & \multicolumn{2}{|c|}{2.4} \\
\hline
\end{tabular}




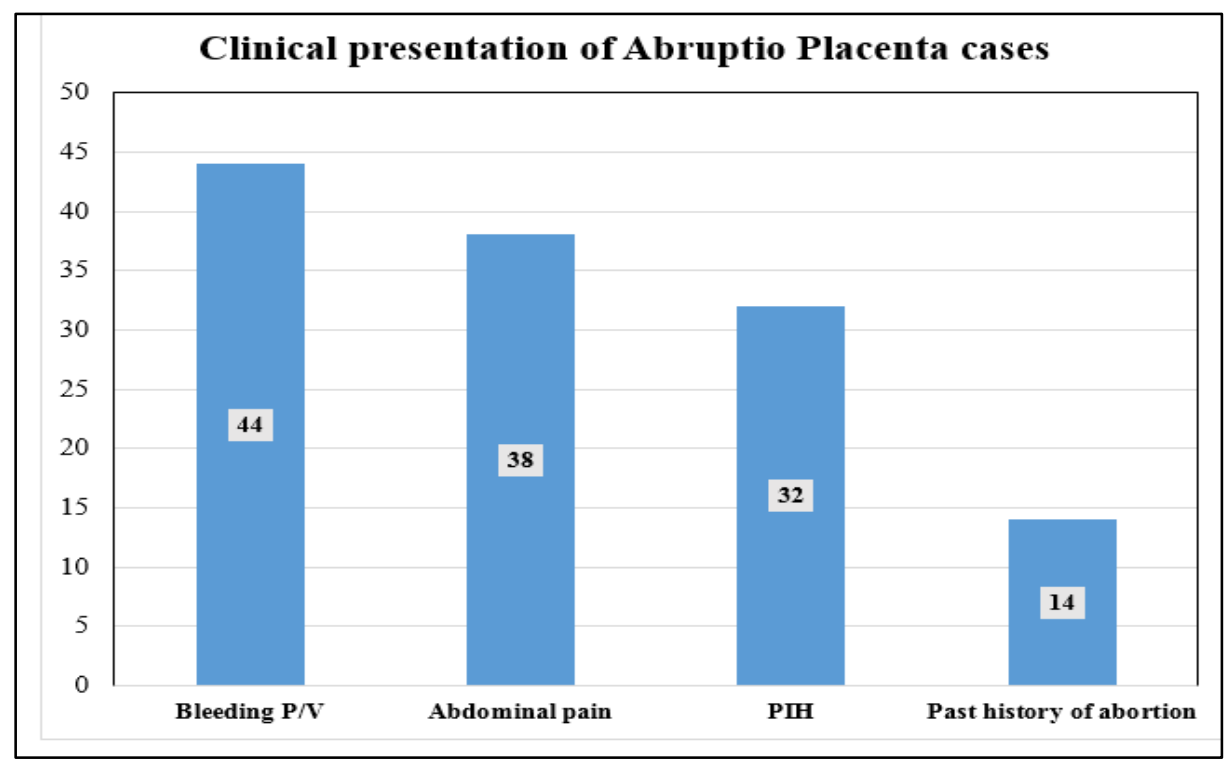

Fig. 1: Distribution of cases according to their clinical presentation

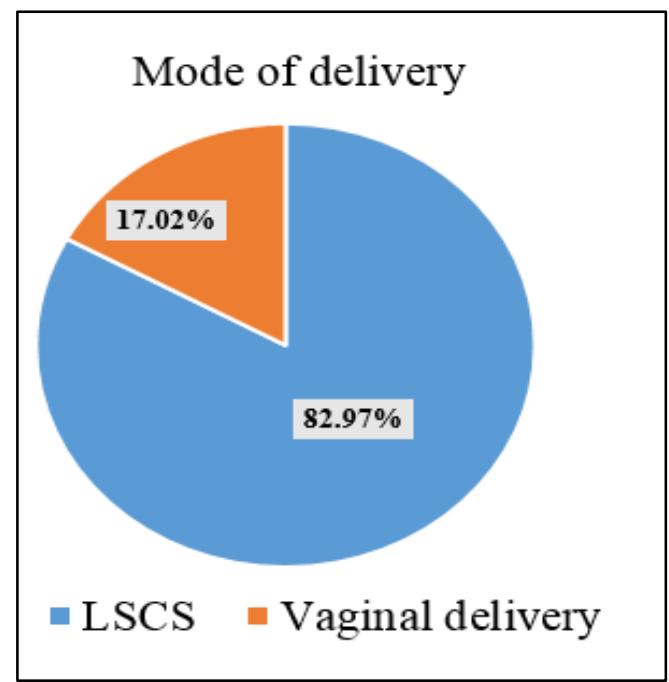

Fig. 2: Distribution of cases according to their modes of delivery

\section{Discussion}

Placental abruption, the premature separation of the placenta, is a serious obstetric complication associated with increased risk of fetal and maternal morbidity and mortality. The most common age of presentation was found to be between 20-30 years with mean age of 26.59 years. Majority of cases belonged to gravida 2 and gravida 3 followed by primigravida. Most of the placental abruption cases presented after 31 weeks of gestation, specifically between 36 to 40 weeks of gestation. Almost all cases complained of bleeding per vaginum, and pain in the abdomen as presenting symptoms. Almost 30\% cases had a previous history of abortions, which was responsible for recurrent losses of pregnancies. $17 \%$ cases were found to be associated with pregnancy-induced hypertension, which itself is a complication of pregnancy, which worsens the outcome.
As a preferred modality, most of the cases $(83 \%)$ were delivered by lower segment caesarian section. Majority of the cases delivered live-born fetuses, out of them almost 56\% newborns required specialized care under NICU. 28\% cases had intrauterine fetal deaths. Pregnancies with placental abruption were appeared to have better obstetric outcomes when diagnosed early and managed using LSCS.

\section{Conclusions}

From the current study, we can conclude that multiparty, cesarean section, previous abortion, and placental abruption can be considered at high risk of placental abruption. Early diagnosis, prenatal follow-up, and management using cesarean section can improve the maternal and fetal outcomes.

\section{References}

1. Elsasser DA, Ananth C V, Prasad V, Vintzileos AM, New Jersey-Placental Abruption Study Investigators $F$ the NJ-PAS. Diagnosis of placental abruption: relationship between clinical and histopathological findings. Eur J Obstet Gynecol Reprod Biol [Internet]. 2010 Feb [cited 2017 Dec 28];148(2):125-30. Available from: http://www.ncbi.nlm.nih.gov/pubmed/19897298

2. Macheku GS, Philemon RN, Oneko O, Mlay PS, Masenga G, Obure J, et al. Frequency, risk factors and feto-maternal outcomes of abruptio placentae in Northern Tanzania: a registry-based retrospective cohort study. BMC Pregnancy Childbirth [Internet]. 2015 Oct 7 [cited 2017 Dec 28];15:242. Available from: http://www.ncbi.nlm.nih.gov/pubmed/26446879

3. Oyelese Y, Ananth C V. Placental Abruption. Obstet Gynecol [Internet]. 2006 Oct [cited 2017 Dec 28];108(4):1005-16. Available from: http://www.ncbi.nlm.nih.gov/pubmed/17012465

4. Hladky K, Yankowitz J, Hansen WF. Placental abruption. Obstet Gynecol Surv [Internet]. 2002 May [cited 2017 Dec 28];57(5):299-305. Available from: http://www.ncbi.nlm.nih.gov/pubmed/11997676 
5. Mukherjee S, Bawa AK, Sharma S, Nandanwar YS, Gadam M. Retrospective study of risk factors and maternal and fetal outcome in patients with abruptio placentae. J Nat Sci Biol Med [Internet]. 2014 Jul [cited 2017 Dec 28];5(2):425. Available from: http://www.ncbi.nlm.nih.gov/pubmed/25097428

6. Ghaheh HS, Feizi A, Mousavi M, Sohrabi D, Mesghari L, Hosseini Z. Risk factors of placental abruption. J Res Med Sci [Internet]. 2013 May [cited 2017 Dec 28];18(May):422-6. Available from: http://www.pubmedcentral.nih.gov/articlerender.fcgi?arti $\mathrm{d}=3810579 \&$ tool $=$ pmcentre $\&$ rendertype $=$ abstract

7. Salari Z, Mirzaie F MM. Evaluation of relationship between opioid addiction and placental abruption. Sci J Hamadan Univ Med Sci Heal Serv. 2008;14:39-43.
8. Choudhary D, Rathi Somani D, Somani D. Evaluation of Risk factors and Obstetric and Perinatal Outcome in Abruptio Placenta. IOSR J Dent Med Sci. Ver VII [Internet]. 2015;14(5):2279-861. Available from: www.iosrjournals.org

9. Han CS, Schatz F, Lockwood CJ. Abruption-associated prematurity. Clin Perinatol. 2011;38(3):407-21.

How to cite this article Patil S, Kapse A. Assessment of abruptio placentae cases in M.G.M. healthcare institute, Kalamboli: A cross-sectional study. Ind J Obsted Gynecol Res. 2018;5(3):335-338. 